\title{
Abundance of Mepraia spinolai in a Periurban Zone of Chile
}

\author{
PedroECattan $/{ }^{+}$,Angélica Pinochet, Carezza Botto-Mahan*, Mariana I Acuña, \\ Mauricio Canals*
}

\author{
Departamento de Ciencias Biológicas, Facultad de Ciencias Veterinarias *Departamento de Ciencias Ecológicas, \\ Facultad de Ciencias, Universidad de Chile, Casilla 2, Correo 15, La Granja, Santiago, Chile
}

Mepraia spinolai is a silvatic species of Triatominae which prefers microhabitats near to or in rock piles. It is also able to maintain similar or higher size populations near houses. The density of bugs in quarries near Santiago, Chile, differed within microhabitats and varied significantly within sites according to season. M. spinolai was not found in sites characterized by human perturbation of quarries. Our results confirm M. spinolai as a silvatic triatomine whose importance as a vector of Chagas disease will depend on contact with humans. This could occur if the habitats where populations of this species are found become exploited for the building of urban areas.

Key words: Mepraia spinolai - relative abundance - population density - Chagas disease - Chile

Mepraia spinolai (Hemiptera, Reduviidae, Triatominae) is the only sylvatic vector of Chagas disease in Chile, and the only species of Triatominae to show marked alary polymorphism (Schofield et al. 1998). It occurs in arid regions of the north and central parts of the country (Canals et al. 1998, 1999) and also on some off-shore islands (Sagua et al. 2000) roughly between $18^{\circ}$ and $34^{\circ} \mathrm{S}$, although the northern forms have recently described as a separate species, M. gajardoi (Frías et al. 1998). In general M. spinolai seems mainly associated with rockpile habitats, and although it has often been found infected with Trypanosoma cruzi (eg. Ordenes et al. 1996) the parasite strain has usually been found to be different to the strain most commonly found infecting humans in Chile (Schofield 1994). Nevertheless, there is concern that $M$. spinolai may adapt to a closer association with humans, representing a possible risk for vector borne transmission of Chagas disease. The aim of the present study was to examine seasonal abundance of $M$. spinolai in a periurban region close to the city of Santiago.

\section{MATERIALS AND METHODS}

The study was carried out in the locality of Colina $(33.12 \mathrm{~S}, 70.43 \mathrm{~W})$ approximately $20 \mathrm{~km}$ from center of Santiago, during the period from October 1997 to September 1998. This locality is characterized as semi-arid, with extensive slate quarries and a few houses.

We considered habitats in two areas (Fig. 1): domestic (DOM) which we defined as areas within $20 \mathrm{~m}$ of human dwellings, and wild (WILD), which were areas $4 \mathrm{~km}$ from the nearest house. Within each of these we distinguished three types of microhabitats. In the DOM areas we examined (i) a stone quarry (CAND), (ii) peridomiciliary struc-

This work was founded by FONDECYT 1980768 to PEC. ${ }^{+}$Corresponding author. Fax: +56-2-6785526. E-mail: pcattan@uchile.cl

Received 17 January 2001

Accepted 19 December 2001 tures (PER) such as animal yards, cellars, and piles of fire wood, and (iii) pile of stones (PIE). In the wild areas we examined (i) drystone walls separating fields (PIR), (ii) a rocky slope near a stone quarry (LAD) and (iii) the stone quarry itself (CANS). Within each microhabitat we considered six sampling points of $4 \mathrm{~m}^{2}$ each. Each month for each sampling point we recorded the number and developmental stage of bugs encountered in a $20 \mathrm{~min}$ period. In addition we used the Lincoln-Bailey mark-recaptured index (Caughley 1978), to estimate the absolute density of M. spinolai in the wild quarry site (CANS) where the bugs appeared most abundant. For this, the captured bugs in two quadrants of $1 \mathrm{~m}^{2}$ were marked with non-toxic red powder on the connexivum, release within $1 \mathrm{~h}$ of capture at the centre of the quadrant, with the second search and capture carried out $5 \mathrm{~h}$ later.

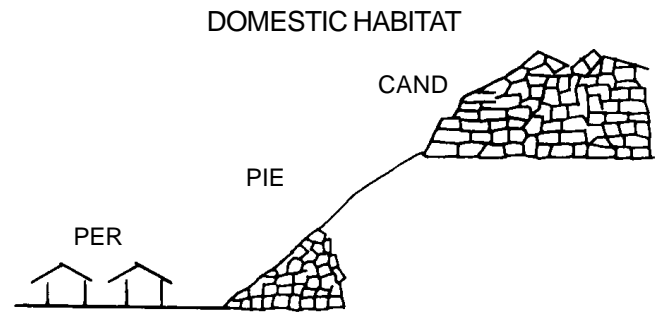

WILD HABITAT

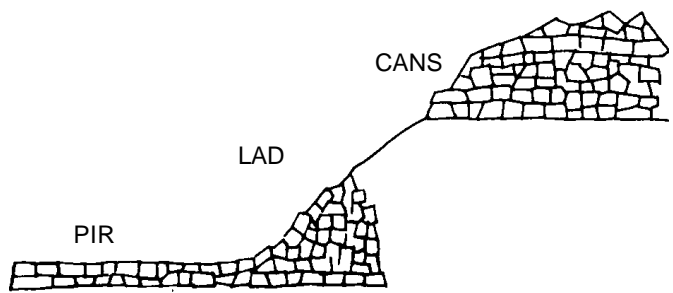

Fig. 1: sampling areas of Mepraia spinolai. Domestic (DOM) and wild (WILD) macrohabitats, respectively. A stone quarry (CAND), peridomiciliary structures as animal yards, cellars, pile of fire wood etc. (PER) and pile of stones (PIE) in macrohabitat DOM. Drystone wall separating fields (PIR), a rocky slope near the stone quarry (LAD) and the stone quarry (CANS) in macrohabitat WILD. 


\section{RESULTS}

No bugs were encountered in the PIE and PER of the "domestic" area. The observed abundance of M. spinolai differed between the other sites (Friedman $=20.81$, p < $0.01)$ and also varied within sites according to season $($ Friedman $=19.4, \mathrm{p}=0.05)$ (Fig. 2). Multiple comparisons showed that microhabitats CANS, LAD and CAND were most similar in relative abundance, with CAND having the highest overall abundance and PIR the lowest. The overall average abundance was about 10 insects captured per hour (range 0-181).

The estimated density of bugs at sites in the stone quarry (CANS) varied over the year (Kruskall-Wallis = $20.1, \mathrm{p}<0.05$ ) (Table) although there were no significant differences in the estimated density between the sampling quadrants points (Kruskall-Wallis $=2.78, \mathrm{p}>0.05$ ). The maximum overall density for both sites was estimated for the summer months, February - March (Table ) with 2nd and 3rd instars predominating in autumm and winter, 5th instars predominating in the spring, and adults, 5th and 1st instars predominating in the summer (Fig. 3).

\section{DISCUSSION}

Our results indicate that in this periurban region, $M$. spinolai is most abundant in the stone quarries themselves, rather than among neighbouring peridomestic habitats, and that its abundance in the quarries seems unaffected by the presence of nearby human dwellings. We consider that its abundance in the stone quarry reflects the relatively constant climatic conditions within the slate cracks, because our recordings showed constant temperatures about $20^{\circ} \mathrm{C}$ at $15 \mathrm{~cm}$ depth, even when the ambient temperature was above $30^{\circ} \mathrm{C}$. This temperature does not differ significantly from the preferred temperature for this

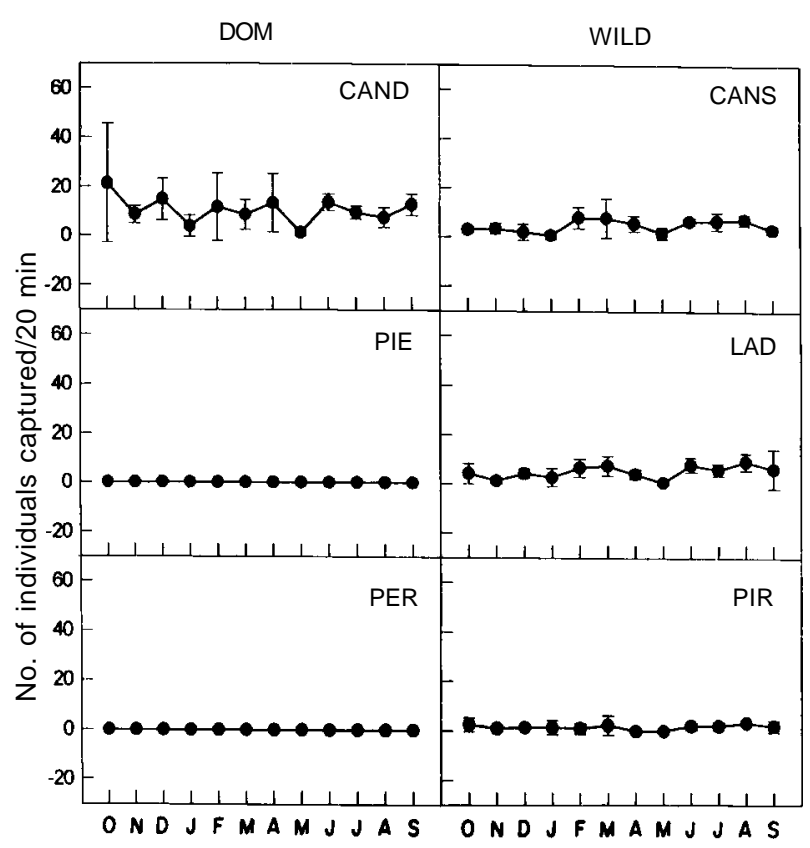

Fig. 2: monthly captures of Mepraia spinolai in the micro-habitats (average \pm 1 standard deviation). Abbreviations as in Fig. 1 .
TABLE

Population density estimations of Mepraia spinolai in two sites located at stone quarry (individuals $/ \mathrm{m}^{2}$ \pm 1 standard error)

\begin{tabular}{lcc}
\hline Month & Site 1 & Site 2 \\
\hline October & 0 & 0 \\
November & 0 & 0 \\
December & 0 & 0 \\
January & $66 \pm 19.1$ & 0 \\
February & $237 \pm 49.1$ & $364 \pm 89.5$ \\
March & $198 \pm 36.4$ & $71 \pm 10.7$ \\
April & $15 \pm 8.4$ & 0 \\
May & $30 \pm 20.9$ & $16 \pm 1.0$ \\
Jun & $36 \pm 15.2$ & $37 \pm 14.8$ \\
July & $47 \pm 9.5$ & $31 \pm 14.8$ \\
August & $80 \pm 33.9$ & $54 \pm 21.3$ \\
September & $24 \pm 2.6$ & $21 \pm 7.5$ \\
\hline
\end{tabular}

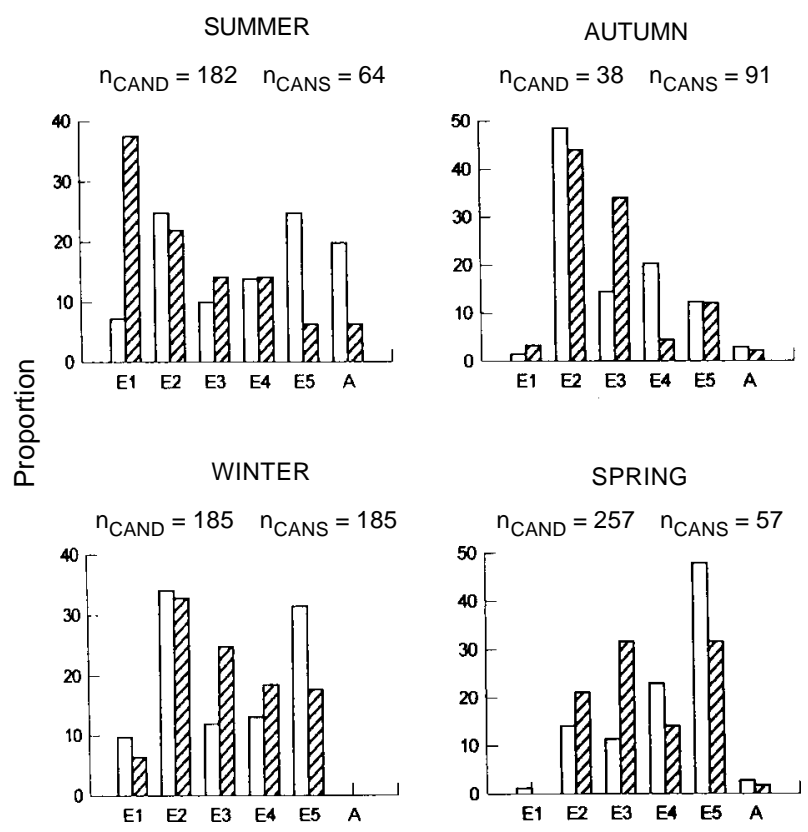

Fig. 3: seasonal distribution of the proportion of the different nymph instars and adults (E1 to adults) in the total captures in the stone quarry (CAND) ( $\square)$ and CANS $(\square)$ sites.

species, of $24.8^{\circ} \mathrm{C}$ recorded in experimental laboratory conditions (Canals et al. 1997). Additionally, the stone quarry habitat appear to offer an abundance of potential host species - mainly rodents, rabbits and the marsupial Thylamys elegans. The high density of bugs in quarries near human dwellings could be indicative of a slow but progressive aproximation to sources of blood from different hosts, including humans and companion fauna. Adults bugs were present in the samples during warm and hot weather, and first instars were represented throughout the year with a peak during summer months, which we interpret to indicate a main reproductive period during spring and summer as also suggested by Schofield et al. (1998) from studies of northern populations of M. spinolai. 
Schofield et al. (1998) found that inland population of this species in northern Chile showed balanced alary polymorphism whereas adults from coastal populations were invariably wingless. The overall proportion of winged males found in our samples was 7\% but dispersal flights were never observed. Human blood index for M. spinolai shows that this bug is not yet an important vector for $T$. cruzi, notwithstanding recently reported levels of $4.6 \%$ (Canals et al. 2001) lightly superior to the $2.4 \%$ reported previously. High density of this species in quarries near human dwellings and the reported increase of the human blood index could suggest a possible sinanthrophic process of M. spinolai.

\section{ACKNOWLEDGEMENTS}

To June Morrison and two anonymous reviewers for helpful suggestions to improve the manuscript. To Mildred Ehrenfeld for her colaboration in the field.

\section{REFERENCES}

Canals M, Cruzat L, Molina MC, Ferreira A, Cattan PE 2001. Blood host sources of Mepraia spinolai (Heteroptera; Reduviidae), wild vector of Chagas disease in Chile. J Med Entomol 38: 303-307

Canals M, Ehrenfeld M, Solís R, Cruzat L, Pinochet A, Tapia C, Cattan PE 1998. Biología comparada de Mepraia spinolai en condiciones de laboratorio y terreno: cinco años de estudio. Parasitol al Día 22: 72-78.
Canals M, Solís R, Tapia C, Ehrenfeld M, Cattan PE 1999. Comparison of some behavioral and physiological feeding parameters of Triatoma infestans Klug, 1834 and Mepraia spinolai Porter, 1934, vectors of Chagas disease in Chile. Mem Inst Oswaldo Cruz 94: 687-692.

Canals M, Solís R, Valderas J, Ehrenfeld M Cattan PE 1997. Preliminary studies on temperature selection and activity cycles of Triatoma infestans and T. spinolai (Heteroptera: Reduviidae), Chilean vectors of Chagas disease. J Med Entomol 34: 11-17.

Caughley G 1978. Analysis of Vertebrate Populations, Interscience Publications, New Jersey, 233 pp.

Frías D, Henry A, González CR 1998. Mepraia gajardoi: a new species of Triatomidae (Hemiptera: Reduviidae) from Chile and its comparison with Mepraia spinolai. Rev Chile Hist Nat 71: 177-188.

Ordenes HV, Ehrenfeld M, Cattan PE, Canals M 1996. Infección Tripano-triatomina de Triatoma spinolai en una zona de riesgo epidemiológico. Rev Med Chile 124: 1053-1057.

Sagua H, Araya J, González J, Neira I 2000. Mepraia spinolai in the Southeastern Pacific Ocean Coast (Chile) - First insular record and feeding pattern on the Pan de Azucar Island. Mem Inst Oswaldo Cruz 95: 167-170.

Schofield CJ 1994. Triatomine, Biología y Control, Eurocommunica Pub., Sussex, 80 pp.

Schofield CJ, Apt W, Sagua H, Panzera F, Dujardin JP 1998. Alary polymorphism in Triatoma spinolai and its possible relationship with demographic strategy. Med Vet Entomol 12: 30-38. 